\title{
Lipid Profile During Pregnancy in HIV-Infected Women
}

\author{
M. Floridia, ${ }^{1}$ E. Tamburrini, ${ }^{2}$ M. Ravizza, ${ }^{3}$ C. Tibaldi, ${ }^{4}$ M.F. Ravagni Probizer, ${ }^{5}$ G. Anzidei, ${ }^{6}$ \\ M. Sansone, ${ }^{7}$ F. Mori, ${ }^{8}$ E. Rubino, ${ }^{9}$ M. Melii, ${ }^{10}$ S. Dalzero, ${ }^{3}$ and G. Guaraldi, ${ }^{11}$ \\ for The Italian Group on Surveillance on Antiretroviral Treatment in Pregnancy*
}

${ }^{1}$ Department of Drug Research and Evaluation, Istituto Superiore di Sanità (ISS), Rome; ${ }^{2}$ Department of Infectious Diseases, Catholic University, Rome; ${ }^{3}$ University of Milan, Dept. Obstet. Gynecol., and S. Paolo Hospital, Milan; ${ }^{4}$ University of Turin, Dept. Obstet. Gynecol., and A.O. OIRM S. Anna, Turin; IIRCCS "S. Matteo", Dept. Obstet. Gynecol., Pavia; ${ }^{6}$ INMI L. S pallanzani, Rome; ${ }^{7}$ Dept. Obstet. Gynecol, University Federico II of Naples; ${ }^{8}$ Infermi Hospital, Rimini; ${ }^{9} \mathrm{Clin}$. Obstet. Gynecol, University of Palermo; ${ }^{10}$ Infectious Diseases Unit, Careggi Hospital, Florence; ${ }^{11}$ Department of Medical Specialities, Infectious Diseases Clinic, University of Modena and Reggio Emilia, Modena, Italy

\begin{abstract}
Purpose: We investigated the evolution of serum lipid levels in HIV-infected pregnant women and the potential effect of antiretroviral treatment during pregnancy using data from a national surveillance study. Method: Fasting lipid measurements collected during routine care in pregnancy were used, analyzing longitudinal changes and differences in lipid values at each trimester by protease inhibitors (PIs) and stavudine use. Multivariate analyses were used to control for simultaneous factors potentially leading to hyperlipidemia. Study population included 248 women. Results: Lipid values increased progressively and significantly during pregnancy: mean increases between the first and third trimesters were $141.6 \mathrm{mg} / \mathrm{dL}$ for triglycerides $(p<.001), 60.8 \mathrm{mg} / \mathrm{dL}$ for total cholesterol ( $p<.001), 13.7 \mathrm{mg} / \mathrm{dL}$ for HDL cholesterol $(p<.001)$, and $17.8 \mathrm{mg} / \mathrm{dL}$ for LDL cholesterol $(p=.001)$. At all trimesters, women on PIs had significantly higher triglyceride values compared to women not on PIs. The effect of PIs on cholesterol levels was less consistent. Stavudine showed a dyslipidemic effect at first trimester only. Multivariate analyses confirmed these observations and suggested a potential role of other cofactors in the development of hyperlipidemia during pregnancy. Conclusion: The changes observed point to the need to further explore the causes and the clinical correlates of hyperlipidemia during pregnancy in women with HIV.
\end{abstract}

Key words: cholesterol, HIV, pregnancy, protease inhibitors, triglycerides

H IV infection, pregnancy, and HAART regimens represent different conditions that have all been independently associated with changes in serum lipids. ${ }^{1-3}$ With respect to antiretroviral treatment, it is currently believed that the risk of dyslipidemia may be higher in the case of treatment with protease inhibitors (PIs) ${ }^{3}$ or stavudine. ${ }^{4}$ Even if pregnancy is characterized by important metabolic changes, little is known at present about the evolution of lipid serum levels during pregnancy in HIV-infected women and about the effect of antiretroviral drugs on such levels during pregnancy. Information on these issues may be relevant for the care of pregnant women with HIV.

\footnotetext{
*A complete list of group members is found in the Appendix.
}

We used data from an ongoing national surveillance study of pregnant women with HIV to define serum lipid changes during pregnancy in HIV-infected women and the effect of PIs and stavudine on triglyceride and cholesterol serum levels during all three trimesters of pregnancy.

For correspondence or reprints contact: Marco Floridia, Department of Drug Evaluation and Research, Istituto Superiore di Sanità, Viale Regina Elena 299, 00161 Rome, Italy. Email: floridia@iss.it

HIV Clin Trials 2006;7(4):184-193 (C) 2006 Thomas Land Publishers, Inc. www.thomasland.com

doi:10.1310/hct0704-184 


\section{METHOD}

The National Program on Surveillance on Antiretroviral Treatment in Pregnancy is an ongoing national surveillance study established in Italy in 2001 to collect information on the safety and efficacy of antiretroviral treatment in pregnancy. The study is observational, and the data collected reflect routine clinical care at each participating center. Only HIV-positive pregnant women are included, and no indication is given for treatment of HIV infection or prophylaxis for mother-to-child transmission, which are defined by the treating physician. Informed consent is required for all enrolled women, using a patient information sheet that has received approval by the competent Ethics Committee.

All the results reported here are based on the data extracted from the general database on January 10, 2006. Lipid values were collected during routine clinical visits in pregnancy at the participating centers. The levels of triglycerides and of total and fractionated (HDL and LDL) cholesterol were measured locally at each center, with samples collected in fasting conditions. All the women with triglyceride and/or cholesterol measurements available at first trimester of pregnancy were considered for the purpose of this article.

Baseline quantitative variables were compared using the $t$ test for independent samples. Categorical variables were compared using the Pearson chisquare test. Differences in mean serum lipid values between trimesters were analyzed by the $t$ test for paired samples. Antiretroviral treatment at each trimester was categorized according to PI and stavudine use or nonuse at the time of blood sampling, and lipid levels were compared in women receiving or not receiving stavudine or PIs at each trimester by the $t$ test for independent samples.

The occurrence of hyperlipidemia during pregnancy was assessed as the proportion of women at each trimester with triglyceride values higher than $200 \mathrm{mg} / \mathrm{dL}$ and/or cholesterol values higher than $240 \mathrm{mg} / \mathrm{dL}$, according to the NCEP ATP III thresholds. ${ }^{5}$ Due to the effect of pregnancy in increasing triglyceride levels, the proportion of women with third trimester triglyceride values above $400 \mathrm{mg}$ / $\mathrm{dL}$ was also calculated. All the above thresholds were used as outcome measures in univariate logistic regression analyses based on the following independent variables: HCV and HBV status (posi- tive vs. negative), age ( $\leq 32$ vs. $>32$ ), and body mass index collected at study entry, plus use or nonuse of PIs, use or nonuse of stavudine, any ongoing antiretroviral treatment, CD4 count ( $<250$ vs. $\geq 250 / \mathrm{mm}^{3}$ ), and HIV-1 RNA viral load values ( $<1000$ vs. $\geq 1000$ copies $/ \mathrm{mL}$ ) registered at the time of blood sampling. We also performed multivariate logistic regression analyses based on the same outcomes in which only the covariates showing a significance level below .15 in univariate analysis were considered. All the analyses were performed using the SPSS software, version 11.0.1, 2001 (SPSS Inc., Chicago, USA).

\section{RESULTS}

As of January 10, 2006, 248 women had triglyceride or cholesterol measurements available at the first trimester of pregnancy (Table 1).

Overall, all serum lipids considered increased steadily across the three trimesters of pregnancy (Figure 1, Table 2). The increases between trimesters were highly significant for all parameters (triglycerides, total cholesterol, HDL and LDL cholesterol; Table 3). Mean increases between first and third trimesters were $141.6 \mathrm{mg} / \mathrm{dL}$ for triglycerides $(p<.001), 60.8 \mathrm{mg} / \mathrm{dL}$ for total cholesterol $(p<$ $.001), 13.7 \mathrm{mg} / \mathrm{dL}$ for HDL cholesterol $(p<.001)$, and $17.8 \mathrm{mg} / \mathrm{dL}$ for LDL cholesterol $(p=.001)$. The total cholesterol/HDL cholesterol ratio (TC/HDLC) remained substantially unchanged during pregnancy (mean values at first, second, and third trimester: 3.50, 3.32, and 3.50, respectively).

As expected, coverage with antiretroviral therapy increased with the advancing of pregnancy $(50.0 \%, 90.8 \%$, and $98.1 \%$, respectively, at first, second, and third trimester), with a parallel increase in use of PIs $(22.4 \%, 40.1 \%$, and $47.5 \%$, respectively). Use of stavudine, conversely, was relatively constant $(18.1 \%, 22.0 \%$, and $22.0 \%$, respectively).

To assess the possible role of PIs and stavudine on lipid concentrations, we first compared triglyceride and cholesterol values between groups of pregnant women taking and not taking such drugs at each trimester. Women on PI treatment had significantly higher triglyceride values at all trimesters compared to women not on PI treatment at the same time (Table 4).

Treatment with PIs had a less pronounced effect on total cholesterol: as observed for triglycerides, 


\section{Table 1. General characteristics}

\begin{tabular}{|c|c|c|}
\hline & Median & Range \\
\hline $\begin{array}{l}\text { Age (years) at conception }(n=247) \\
\text { Body mass index at conception }(n=210) \\
\text { CD4 cells } / \mathrm{mm}^{3} \text { at conception }(n=191)\end{array}$ & $\begin{array}{l}33 \\
21.8 \\
495\end{array}$ & $\begin{array}{c}19-43 \\
16.2-40.7 \\
23-1376\end{array}$ \\
\hline $\mathrm{CD} 4$ cells $/ \mathrm{mm}^{3}$ at conception $(\mathrm{n}=191)$ & $\mathrm{n}$ & $\%$ \\
\hline \multicolumn{3}{|l|}{ Route of transmission ( $n=245$ ) } \\
\hline Sexual & 172 & 70.2 \\
\hline IV drug use & 46 & 18.8 \\
\hline Unknown & 24 & 9.8 \\
\hline Transfusion/other & 3 & 1.2 \\
\hline \multicolumn{3}{|l|}{ Nationality ( $n=248$ ) } \\
\hline Italian & 185 & 74.6 \\
\hline Non-Italian & 63 & 25.4 \\
\hline \multicolumn{3}{|l|}{ HIV CDC clinical status at conception $(n=244)$} \\
\hline Asymptomatic & 197 & 80.7 \\
\hline Symptomatic, non-AIDS & 32 & 13.1 \\
\hline AIDS & 15 & 6.1 \\
\hline \multicolumn{3}{|l|}{ Coinfections $(n=230)$} \\
\hline $\mathrm{HCV}$ & 63 & 27.4 \\
\hline HBV & 30 & 13.1 \\
\hline \multicolumn{3}{|l|}{ On antiretroviral treatment at conception $(n=246)$} \\
\hline Yes & 150 & 61.0 \\
\hline No & 96 & 39.0 \\
\hline \multicolumn{3}{|l|}{ Number of drugs at conception $(n=246)$} \\
\hline None & 96 & 39.2 \\
\hline Two & 18 & 7.3 \\
\hline Three or more & 132 & 53.5 \\
\hline \multicolumn{3}{|l|}{ Antiretroviral treatment history $(\mathrm{n}=246)$} \\
\hline Treatment-experienced & 186 & 75.6 \\
\hline Treatment-naive & 60 & 24.4 \\
\hline \multicolumn{3}{|l|}{ Indication for antiretroviral treatment $(n=220)$} \\
\hline For the health of the mother & 169 & 76.8 \\
\hline Only for the prevention of MTCT & 51 & 23.2 \\
\hline \multicolumn{3}{|l|}{ Use of Pls } \\
\hline First trimester (n with information available $=241$ ) & 54 & 22.4 \\
\hline Second trimester ( $\mathrm{n}$ with information available $=207$ ) & 83 & 40.1 \\
\hline Third trimester ( $\mathrm{n}$ with information available $=200$ ) & 95 & 47.5 \\
\hline \multicolumn{3}{|l|}{ Use of stavudine } \\
\hline First trimester (n with information available = 232) & 42 & 18.1 \\
\hline Second trimester ( $\mathrm{n}$ with information available $=205$ ) & 45 & 22.0 \\
\hline Third trimester (n with information available = 205) & 45 & 22.0 \\
\hline
\end{tabular}

\footnotetext{
Note: $\mathrm{MTCT}=$ mother-to-child transmission; $\mathrm{PIs}=$ protease inhibitors .
} 


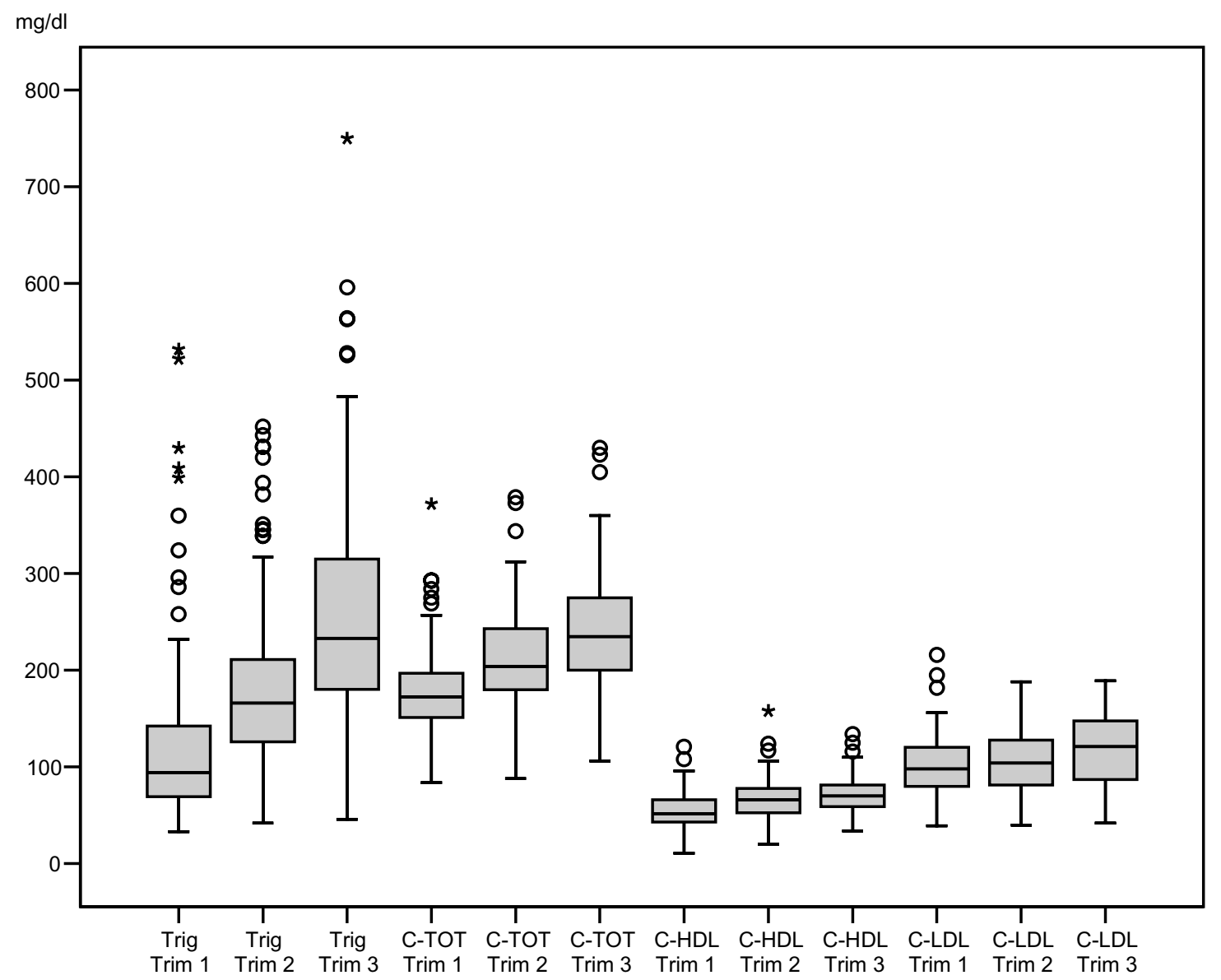

Figure 1. Serum triglyceride and cholesterol levels (total cholesterol, HDL- and LDL-cholesterol) during pregnancy, by trimester. Trig = triglycerides; C - TOT $=$ Total cholesterol; $\mathrm{C}-\mathrm{HDL}=\mathrm{HDL}$ cholesterol; $\mathrm{C}-\mathrm{LDL}=\mathrm{LDL}$ cholesterol; Trim $=$ Trimester of pregnancy. Values are reported in $\mathrm{mg} / \mathrm{dL}$. Black lines indicate median values; the boxes indicate interquartile range; the circles denote values with a distance from the median between 1.5 and 3 times the interquartile distance; and asterisks indicate values with a distance from the median greater than 3 times the interquartile distance.

both groups showed a progressive increase from first to third trimester, with consistently higher values at each trimester for PI-treated women. The difference, however, was limited and did not reach statistical significance at any trimester. No significant differences in HDL cholesterol, in LDL cholesterol, and in TC/HDL-C ratio at any trimester were observed between women taking and not taking PIs (data not shown).

To exclude that the higher triglyceride levels observed in women receiving PIs were due to a general dyslipidemic effect of antiretroviral therapy
(ARV), we performed a confirmatory analysis in which women not on PIs were further divided into two groups (women on non-PI-based ARV and women not on treatment). This analysis confirmed that the observed effect was PI specific: compared to women on PIs, women on non-PI-based ARV (mostly represented by three-drug regimens) had significantly lower triglyceride levels at all trimesters $(112.7,171.1$, and $228.3 \mathrm{mg} / \mathrm{dL}$, respectively; $p$ $=.009, .021$, and .001). Conversely, no significant differences in triglyceride levels were observed between women on non-PI-based ARV treatment 
Table 2. Lipid profile in HIV-positive women by trimester of pregnancy

\begin{tabular}{|c|c|c|c|}
\hline & First trimester & Second trimester & Third trimester \\
\hline \multicolumn{4}{|l|}{ Triglycerides, mg/dL } \\
\hline Available, $n$ & 232 & 187 & 172 \\
\hline Mean & 115 & 180 & 254 \\
\hline Median & 94 & 166 & 233 \\
\hline Interquartile range & $69-142$ & $126-212$ & $180-315$ \\
\hline Range & $33-532$ & $42-452$ & 46-750 \\
\hline Levels >200 mg/dL, n (\%) & $17(7.3 \%)$ & $57(30.5 \%)$ & $115(66.9 \%)$ \\
\hline Levels >400 mg/dL, n (\%) & $4(1.7 \%)$ & $5(2.7 \%)$ & $22(12.8 \%)$ \\
\hline \multicolumn{4}{|l|}{ Total cholesterol, mg/dL } \\
\hline Available, $\mathrm{n}$ & 238 & 186 & 167 \\
\hline Mean & 176 & 210 & 238 \\
\hline Median & 172 & 204 & 235 \\
\hline Interquartile range & $151-197$ & $180-243$ & $200-277$ \\
\hline Range & $84-372$ & 88-379 & $106-430$ \\
\hline Levels >240 mg/dL, n (\%) & $15(6.3 \%)$ & $49(26.3 \%)$ & $79(47.3 \%)$ \\
\hline \multicolumn{4}{|l|}{ HDL cholesterol, mg/dL } \\
\hline Available, $\mathrm{n}$ & 138 & 120 & 103 \\
\hline Mean & 55 & 67 & 71 \\
\hline Median & 51 & 66 & 70 \\
\hline Interquartile range & $43-66$ & $52-78$ & $59-82$ \\
\hline Range & $11-121$ & $20-158$ & $34-134$ \\
\hline \multicolumn{4}{|l|}{ LDL cholesterol, mg/dL } \\
\hline Available, $\mathrm{n}$ & 75 & 72 & 59 \\
\hline Mean & 100 & 106 & 117 \\
\hline Median & 98 & 104 & 121 \\
\hline Interquartile range & $80-121$ & $81-128$ & $87-150$ \\
\hline Range & $39-216$ & $40-188$ & $42-189$ \\
\hline
\end{tabular}

and women not on ARV, who had levels at first and second trimester of 97.4 and $153.4 \mathrm{mg} / \mathrm{dL}$, respectively $(p>.05)$; no comparison was made at third trimester for women not on ARV because only four women were not receiving ARV at that time.

A similar analysis based on stavudine use showed an apparent dyslipidemic role of stavudine at first trimester only, with higher values of triglycerides (mean difference: $45.0 \mathrm{mg} / \mathrm{dL}, 95 \%$ CI 6.8-83.4, $p=.022$ ) and total cholesterol (mean difference: $19.5 \mathrm{mg} / \mathrm{dL}, 95 \%$ CI 2.3-36.7, $p=.027$ ) among women taking this drug. This effect was not present at the second and third trimesters, and stavudine also showed no effect at any trimester on cholesterol fractions (HDL and LDL cholesterol) and on TC/HDL-C ratio (data not shown).
Overall, the occurrence of hypertriglyceridemia and hypercholesterolemia according to the NCEP thresholds was relatively common and appeared to be increasingly frequent with the advancing of pregnancy $(66.9 \%$ and $47.3 \%$, respectively, at third trimester; Table 2).

Univariate logistic regression models suggested a potential role of multiple factors on hyperlipidemia. To assess their independent role, multivariate logistic regression analyses were performed. Such analyses showed that at both first and second trimesters use of PIs was significantly and independently associated with triglyceride levels above $200 \mathrm{mg} / \mathrm{dL}$, with a nine-fold increase in risk of hypertriglyceridemia at first trimester and a twofold increase at second trimester, compared to nonuse of PIs (Table 5). At third trimester, this associa- 
Table 3. Mean differences in lipid values between subsequent trimesters

\begin{tabular}{llccrr}
\hline Measurement & Trimesters considered & $\mathrm{n}$ & $\begin{array}{c}\text { Average difference } \\
\text { (mg/dL) }\end{array}$ & $\begin{array}{c}\text { 95\% CI for the } \\
\text { difference }\end{array}$ & $\mathrm{p}$ \\
\hline Triglycerides & From Tr. I to Tr. II & 178 & +66.4 & $55.5-77.2$ & $<.001$ \\
& From Tr. II to Tr. III & 160 & +70.4 & $57.1-83.8$ & $<.001$ \\
& From Tr. I to Tr. III & 162 & +141.6 & $125.0-158.1$ & $<.001$ \\
Total cholesterol & From Tr. I to Tr. II & 179 & +34.2 & $28.2-40.1$ & $<.001$ \\
& From Tr. II to Tr. III & 153 & +24.4 & $18.7-30.1$ & $<.001$ \\
& From Tr. I to Tr. III & 163 & +60.8 & $53.6-68.0$ & $<.001$ \\
HDL cholesterol & & & & & $<.001$ \\
& From Tr. I to Tr. II & 97 & +13.1 & $9.2-17.0$ & .043 \\
& From Tr. II to Tr. III & 88 & +2.3 & $0.1-4.5$ & $<.001$ \\
& From Tr. I to Tr. III & 86 & +13.7 & $10.0-17.4$ & .027 \\
LDL cholesterol & From Tr. I to Tr. II & 53 & +9.8 & $1.1-18.6$ & .012 \\
& From Tr. II to Tr. III & 46 & +8.2 & $1.9-14.5$ & .001 \\
\hline
\end{tabular}

Note: Tr. $=$ trimester.

tion showed a borderline level of significance $(p=$ .055). At the higher threshold of $400 \mathrm{mg} / \mathrm{dL}$, use of PIs was significantly and independently associated with hypertriglyceridemia, with a five-fold increase in risk at third trimester (Table 5).

The results of the multivariate analysis based on cholesterol level above $240 \mathrm{mg} / \mathrm{dL}$ as the outcome measure showed different associations at each trimester (Table 5). No association was found between hypercholesterolemia and use of PIs at any trimester.

\section{DISCUSSION}

Use of antiretroviral treatment during pregnancy is associated with several concerns, which include potential teratogenicity, risk for the exposed and uninfected newborn, possible reduced efficacy of antiretroviral regimens in this particular condition, and safety considerations for the mother, including potentially increased risk of specific adverse events.

Our study provides information on a scarcely

Table 4. Mean differences in cholesterol and triglycerides at each trimester by protease inhibitor (PI) use

\begin{tabular}{|c|c|c|c|c|c|c|}
\hline Mean value & $\mathrm{PI}$ & No PI & $\begin{array}{c}\mathrm{n} \\
(\mathrm{PI} / \mathrm{no} \mathrm{PI})\end{array}$ & $\begin{array}{l}\text { Average } \\
\text { difference } \\
(\mathrm{mg} / \mathrm{dL})\end{array}$ & $\begin{array}{l}95 \% \mathrm{Cl} \\
\text { for the } \\
\text { difference }\end{array}$ & $\mathrm{p}$ \\
\hline \multicolumn{7}{|l|}{ Triglycerides, mg/dL } \\
\hline First trimester & 159.1 & 102.7 & $51 / 177$ & 56.5 & $24.1-88.8$ & .001 \\
\hline Second trimester & 201.8 & 167.4 & $77 / 103$ & 34.3 & $9.2-59.4$ & .008 \\
\hline Third trimester & 286.4 & 231.6 & $82 / 83$ & 54.8 & $19.8-89.7$ & .002 \\
\hline \multicolumn{7}{|c|}{ Total cholesterol, mg/dL } \\
\hline First trimester & 179.9 & 173.8 & $54 / 178$ & 6.1 & $-5.6-17.9$ & .307 \\
\hline Second trimester & 218.2 & 205.4 & $77 / 101$ & 12.8 & $-2.0-27.6$ & .09 \\
\hline Third trimester & 243.3 & 237.7 & $79 / 81$ & 5.6 & $-12.3-23.4$ & .54 \\
\hline
\end{tabular}


Table 5. Variables independently associated to hyperlipidemia in a multivariate analysis

\begin{tabular}{|c|c|c|c|c|}
\hline Outcome & Variable & $\begin{array}{l}\text { Adjusted odds } \\
\text { ratio (AOR) }\end{array}$ & $95 \% \mathrm{Cl}$ & $\mathrm{p}$ \\
\hline $\begin{array}{l}\text { Triglycerides }>200 \mathrm{mg} / \mathrm{dL} \text { at } \\
\text { first trimester }\end{array}$ & Use of PIs & 9.17 & $3.00-28.0$ & $<.001$ \\
\hline $\begin{array}{l}\text { Triglycerides }>200 \mathrm{mg} / \mathrm{dL} \text { at } \\
\text { second trimester }\end{array}$ & Use of Pls & 2.04 & $1.05-3.96$ & .036 \\
\hline $\begin{array}{l}\text { Triglycerides }>200 \mathrm{mg} / \mathrm{dL} \text { at } \\
\text { second trimester }\end{array}$ & Age above 32 years & 2.74 & $1.32-5.70$ & .007 \\
\hline $\begin{array}{l}\text { Triglycerides }>200 \mathrm{mg} / \mathrm{dL} \text { at } \\
\text { third trimester }\end{array}$ & BMI & 1.15 & $1.03-1.29$ & .015 \\
\hline $\begin{array}{l}\text { Triglycerides }>200 \mathrm{mg} / \mathrm{dL} \text { at } \\
\text { third trimester }\end{array}$ & $\begin{array}{l}\text { Coinfection with } \\
\text { HBV }\end{array}$ & 2.87 & $1.07-7.65$ & .035 \\
\hline $\begin{array}{l}\text { Triglycerides }>400 \mathrm{mg} / \mathrm{dL} \text { at } \\
\text { third trimester }\end{array}$ & Use of Pls & 5.80 & $1.82-18.5$ & .047 \\
\hline $\begin{array}{l}\text { Cholesterol }>240 \mathrm{mg} / \mathrm{dL} \text { at } \\
\text { first trimester }\end{array}$ & Use of d4T & 4.97 & $1.41-17.5$ & .012 \\
\hline $\begin{array}{l}\text { Cholesterol }>240 \mathrm{mg} / \mathrm{dL} \text { at } \\
\text { second trimester }\end{array}$ & CD4 cells $>250$ & 9.98 & $1.30-76.8$ & .027 \\
\hline $\begin{array}{l}\text { Cholesterol }>240 \mathrm{mg} / \mathrm{dL} \text { at } \\
\text { second trimester }\end{array}$ & $\begin{array}{l}\text { HIV-RNA below } \\
1000 \text { copies/mL }\end{array}$ & 2.52 & $1.07-5.96$ & .035 \\
\hline $\begin{array}{l}\text { Cholesterol }>240 \mathrm{mg} / \mathrm{dL} \text { at } \\
\text { third trimester }\end{array}$ & CD4 cells $>250$ & 3.82 & $1.00-14.5$ & .05 \\
\hline $\begin{array}{l}\text { Cholesterol }>240 \mathrm{mg} / \mathrm{dL} \text { at } \\
\text { third trimester }\end{array}$ & $\begin{array}{l}\text { Coinfection with } \\
\mathrm{HCV}\end{array}$ & 2.59 & $1.14-5.91$ & .006 \\
\hline
\end{tabular}

Note: PIs = protease inhibitors; BMI = body mass index; HBV = hepatitis B virus; $d 4 T$ = stavudine; HCV = hepatitis C virus.

explored area: the general effect of pregnancy on serum lipid levels in pregnant women with HIV and the effects in pregnancy of some drugs and regimens already known to be able to induce metabolic changes outside pregnancy. We were able to assess levels of cholesterol and triglycerides by trimester, with a detailed description of the dynamic changes observed during pregnancy in women receiving antiretroviral regimens based on different drugs.

A first result of our investigation is the confirmation that pregnancy has an important effect on triglyceride and cholesterol values in HIV-positive women, with a progressive increase from first to third trimester. To our knowledge, this has not been previously documented in the setting of HIV infection. In the entire group, all the changes for triglycerides and cholesterol were significant, and they can be summarized for the last two trimesters of pregnancy in an increase of roughly $70 \mathrm{mg} / \mathrm{dL}$ per trimester for triglycerides and of roughly 30 $\mathrm{mg} / \mathrm{dL}$ per trimester for total cholesterol.

The clinical implications of these findings are uncertain, because of the scarcity of data on this issue. In our study, total cholesterol values increased significantly during pregnancy, but both HDL cholesterol and LDL cholesterol increased significantly, too. As a consequence, the TC/HDL$\mathrm{C}$ ratio, which is considered an important predic- 
tive factor for cardiovascular disease in women, ${ }^{6}$ remained substantially unchanged. This observation is partly reassuring in a context of cardiovascular risk assessment and mitigates the possible concerns raised by the high frequency of hypercholesterolemia.

The frequent occurrence of high levels of triglycerides may also represent a concern. In the general population, hypertriglyceridemia represents an independent risk factor for cardiovascular disease, ${ }^{7}$ and, if severe, may cause pancreatitis. ${ }^{8}$ Cases of pancreatitis induced by severe hypertriglyceridemia have been reported in pregnant women, ${ }^{9}$ and early hypertriglyceridemia has been associated with subsequent development of gestational diabetes mellitus ${ }^{10}$ and early-onset preeclampsia. ${ }^{11}$ In pregnant women with normal glucose tolerance, triglyceride levels measured at midpregnancy or at the third trimester of pregnancy were independent predictors of neonatal birth weight, suggesting a potential independent role on the development of fetal macrosomia. ${ }^{12,13}$ Triglyceride levels, therefore, can be associated with different pathological conditions. Assessing the clinical correlates of hypertriglyceridemia and of hypercholesterolemia in HIV-positive pregnant women is beyond the scope of this article; in future studies, we will assess whether the metabolic changes persist after pregnancy and whether such changes may predict adverse pregnancy outcomes.

We demonstrated that PIs, which are commonly used in pregnancy, have an important effect on lipid profile, enhancing the hyperlipidemic effect of pregnancy. Compared to women not taking PIs, women receiving PIs had constantly higher values of triglycerides at each trimester, with average differences of about 35-50 mg/ dL at different trimesters. This finding was confirmed by multivariate analyses at all trimesters. All these associations were statistically significant and were quantified in a nine-fold increase in risk at first trimester, in a two-fold increase at second trimester (with 200 $\mathrm{mg} / \mathrm{dL}$ as threshold), and in a five-fold risk increase at third trimester (at the higher threshold of $400 \mathrm{mg} / \mathrm{dL}$ ). We also demonstrated that this dyslipidemic effect was not a consequence of antiretroviral treatment in general, because both direct comparisons and multivariate analyses showed no role for non-PI-based antiretroviral treatment in favoring hypertriglyceridemia. Data on total cholesterol also suggest a similar effect of PIs, although less pronounced.
Our data also point to the need to further explore the metabolic effects associated with stavudine. The use of this drug, even if less common compared to PIs, was consistently associated with increased values of triglycerides, with average differences in the range of $17-45 \mathrm{mg} / \mathrm{dL}$. These differences, however, reached statistical significance at the first trimester only. Our data, therefore, though clearly suggestive of a specific role of stavudine in increasing triglycerides during pregnancy, do not allow us to firmly establish it. This issue deserves further investigation and could be reassessed on a wider sample basis.

Both PIs and stavudine showed no significant effect on HDL- or LDL-cholesterol values or on TC/HDL-C value. The increased levels of total cholesterol observed at the first trimester in women taking stavudine also need confirmation on wider samples, because a similar trend was not observed in subsequent trimesters.

Multivariate analyses indicated other possible predictors of dyslipidemia. Age was a significant cofactor in hypertriglyceridemia at the second trimester. Although increasing age is a possible factor for metabolic disease and hyperlipidemia, we believe this finding should be considered cautiously, given the absence of similar findings in the other two trimesters.

The evolution of cholesterol levels also may be relevant in the care of pregnant women with HIV. In our study, cholesterol levels were affected primarily by pregnancy, with no apparent effect of PIs in multivariate analyses at all trimesters. The findings concerning other potential cofactors of hypercholesterolemia were less consistent, and apparently different cofactors were identified at different trimesters: use of stavudine at the first trimester, low RNA levels at the second trimester, $\mathrm{HCV}$ coinfection at the third trimester, and higher CD4 counts at the second and third trimesters. Even if some rationale was found for all these findings, we believe that confirmatory studies are needed to better establish their role.

One limitation of our study is the relatively small number of women receiving stavudine. This factor may actually have prevented us from ascertaining a statistically significant effect of stavudine on triglycerides, which was clinically suggested by the clear trend for higher levels observed in women receiving the drug. It should be considered that use of stavudine in pregnancy may be also relatively less frequent compared to other drugs due to con- 
cerns regarding specific toxicities, such as lactic acidosis in the mothers and mitocondrial disease in the newborns. ${ }^{14,15}$ A greater number of cases collected through a continued surveillance may enable us to reassess this issue in the future.

Among the strengths of our study is the size of the sample, which is taken from a national study involving more than 30 clinical centers. The number of women enrolled also allowed us to perform analyses adjusted for multiple potentially predictive factors, and all the data were collected in a setting of clinical practice and not of clinical trials, which may ensure a better evaluation of treatments presently used in these settings.

It should also be considered that clinical trials, even if able to guarantee more complete and accurate information, are quite difficult to conduct in pregnant women and, in any case, are unlikely to be performed on such a large basis: our observational study, therefore, may represent one of the few possible relevant sources of information on this subject.

The importance of our findings is likely to be enhanced by the recent updates in treatment recommendations regarding nonnucleoside reverse transcriptase inhibitors (NNRTIs), limiting the use of these drugs in women of childbearing age because of possible teratogenicity (efavirenz) and of CD4-level-dependent toxicity. ${ }^{16,17}$ Such limitations are likely to lead to a preferential use of other drugs, particularly PIs, in pregnant women. In this context, we believe that our information may contribute to a comprehensive assessment of potential risks and benefits of different antiretroviral regimens in pregnancy.

\section{ACKNOWLEDGMENTS}

The work was funded through public funds from the Italian National Program on Research on AIDS (grants 39C/A, 31D55, 31D56).

We thank Cosimo Polizzi and Alessandra Mattei for data retrieval and for providing technical secretariat for the study and Tonino Sofia for providing comments and help in the revision of the final manuscript.

\section{REFERENCES}

1. Grinspoon S, Carr A. Cardiovascular risk and body-fat abnormalities in HIV-infected adults. New Engl J Med. 2005;352(1):48-62.
2. Butte NF. Carbohydrate and lipid metabolism in pregnancy: normal compared with gestational diabetes mellitus. Am J Clin Nutr. 2000;71(suppl):1256S-1261S.

3. Friis-Møller N, Weber R, Reiss $P$, et al. Cardiovascular disease risk factors in HIV-patients: association with antiretroviral therapy: results from the DAD study. AIDS. 2003;17:1179-1193.

4. Gallant J E, Staszewski S, Pozniak AL, et al. Efficacy and safety of tenofovir DF vs stavudine in combination therapy in antiretroviral-naive patients: a 3-year randomised trial. LAMA. 2004;292:191-201.

5. Third Report of the National Cholesterol Education Program (NCEP) Expert Panel on Detection, Evaluation, and Treatment of High Blood Cholesterol in Adults (Adult Treatment Panel III) Final Report. Circulation. 2002;106:3143-3421.

6. Ridker PM, Rifai N, Cook NR, et al. Non-HDL cholesterol, apolipoproteins A-I and B100, standard lipid measures, lipid ratios, and CRP as risk factors for cardiovascular disease in women. LAMA. 2005;294:326-333.

7. Hokanson J E, Austin MA. Plasma triglyceride level is a risk factor for cardiovascular disease independent of high-density lipoprotein cholesterol level: a meta-analysis of population-based prospective studies. $\perp$ Cardiovasc Risk. 1996; 3(2):213-219.

8. Yadav D, Pitchumoni CS. Issues in hyperlipidemic pancreatitis. L Clin Gastroenterol. 2003;36(1):54-62.

9. Saadi HF, Kurlander DJ, Erkins J M, Hoogwerf BJ. Severe hypertriglyceridemia and acute pancreatitis during pregnancy: treatment with gemfibrozil. Endocrine Pract. 1999;5(1):33-36.

10. Enquobahrie DA, Williams MA, Qiu C, Luthy DA. Early pregnancy lipid concentrations and the risk of gestational diabetes mellitus. Diabetes Res Clin Pract. 2005;70(2):134-142.

11. Clausen T, Djurovic S, Heriksen T. Dyslipidemia in early second trimester is mainly a feature of women with early onset pre-eclampsia. BJ OG. 2001;108(10):1081-1087.

12. Kitajima M, Oka S, Yasuhi I, et al. Maternal serum triglyceride at 24-32 weeks' gestation and newborn weight in nondiabetic women with positive diabetic screens. Obstet Gynecol. 2001;97:776-780.

13. Maternal triglyceride levels and newborn weight in pregnant women with normal glucose tolerance. Diabetic Med. 2005;22(1):21-25.

14. Sarner L, Fakoya A. Acute onset lactic acidosis and pancreatitis in the third trimester of pregnancy in HIV-1 positive women taking antiretroviral medication. Sex Transm Infect. 2002;78(1):58-59.

15. Blanche S, Tardieu M, Rustin P, et al. Persistent mitochondrial dysfunction and perinatal exposure to antiretroviral nucleoside analogues. Lancet. 1999; 354(9184):1084-1089.

16. Public Health Service Task Force recommendations for use of antiretroviral drugs in pregnant HIV-1-infected women for maternal health and interventions to reduce perinatal HIV-1 transmission in the United States. February 24, 2005. Available at: http://aidsinfo.nih.gov/guidelines/perinatal/PER_022405.pdf. Accessed J une 3, 2005.

17. FDA public health advisory for nevirapine (Viramune). J anuary 19, 2005. Available at: http://www.fda.gov/cder/ drug/advisory/nevirapine.htm. Accessed J uly 10, 2006. 


\section{APPENDIX}

\section{The Italian Group on Surveillance on Antiretroviral Treatment in Pregnancy}

Project Coordinators: M. Floridia, M. Ravizza, E. Tamburrini

Participants: M. Ravizza, E. Tamburrini, P. Ortolani, F. Mori, C. Monticelli, E.R. dalle Nogare, G. Sterrantino, M. Meli, M. Mazzetti, B. Borchi, F. Vichi, E. Pinter, E. Anzalone, L. Roberti, L. Pietrogiacomi, A. Carocci, E. Grilli, A. Maccabruni, A. Moretti, G. Natalini, G. Guaraldi, C. Vanzini, F. Sabbatini, G. Nardini, A. Zoncada, A. Degli Antoni, A. Molinari, P. Rogasi, M.P. Crisalli, E. Chiesa, G. Placido, M. Dalessandro, A. Vivarelli, P. Castelli, F. Savalli, V. Portelli, S. Alberico, M. Bernardon, A. Meloni, A. Citernesi, M.F. Ravagni Probizer, A. Vimercati, B. Guerra, V. Ciardelli, M. Sansone, P. Martinelli, C. Tibaldi, L. Ladetto, S.Marini, G. Masuelli, L. Di Lenardo,
E. Ferrazzi, V. Conserva, T. Brambilla, E. Rubino, A. Bucceri, R. Matrone, G. Scaravelli, G. Anzidei, R. Cavallini, D. Gariel, S. Di Giambenedetto, C. Fundarò, O. Genovese, C. Cafforio, C. Pinnetti, G. Liuzzi, V. Tozzi, P. Massetti, M. Anceschi, A.M. Casadei, F. Montella, A.F. Cavaliere, V. Finelli, C. Riva, M. Cellini, V. Venturi, M. Lanari, S. Garetto, G. Castelli Gattinara, L. Mangiarotti, M. Ierardi, S. Foina, B. Salerio, S. Dalzero, A. Mattei, C. Polizzi, E. Germinario, M.F. Pirillo, R. Amici, C.M. Galluzzo, M. Floridia

Advisory Board: A. Cerioli, M. De Martino, P. Mastroiacovo, M. Moroni, F. Parazzini, G. Pardi, E. Tamburrini, S. Vella

SIGO-HIV Group National Coordinators: E. Ferrazzi, P. Martinelli 